\title{
o poeta no Museu. textos inéditos de João Cabral de Melo Neto
}

Edneia Rodrigues Ribeiro ${ }^{1}$

Talvez, diante da folha em branco te olhava branco esse inimigo que o homem leva no mais fundo e o julga com o olhar mais frio. (João Cabral de Melo Neto) ${ }^{2}$

O HÁBITO DE SE COMEMORAR O CENTENÁRIO DE ESCRITORES, NO BRASIL, TEM REACENDIDO O DEBATE EM TORNO DE SUAS OBRAS. No início de 2020, João Cabral de Melo Neto tornou-se um dos principais assuntos da mídia brasileira, demonstrando que a obra segue viva, mesmo após 20 anos da morte do poeta. Entre notícias sobre eventos, lançamentos de livros e diversas homenagens, uma delas trouxe ainda mais fôlego às comemorações: a descoberta de seus textos inéditos. Este trabalho pretende apresentar os passos da pesquisa e um breve inventário do material encontrado.

A história começa com consultas ao espólio documental de João Cabral para a escrita da tese de doutoramento de minha autoria - Um Museu de duas faces: poesia de circunstância em João Cabral de Melo Neto - defendida, em abril de 2019, no Programa de Pós-graduação em Estudos Literários da Universidade Federal de Minas Gerais (UFMG), sob orientação do professor e poeta Sérgio Alcides. O projeto inicial de tese pretendia analisar poemas de Museu de $t u d o^{3}$ (1975) endereçados a escritores brasileiros, muitos deles amigos de João Cabral: Manuel Bandeira, Joaquim Cardozo, Marques Rebelo, Willy Lewin, Vinicius de Moraes, Lêdo Ivo, Rubem Braga e Gilberto Freyre. Parte do trabalho envolvia consultas a documentos de cunho mais subjetivo, como, por exemplo, as cartas trocadas entre eles.

Nosso primeiro contato com documentos de fontes primárias de João Cabral, que se encontra no ArquivoMuseu de Literatura Brasileira (AMBL), da Fundação Casa de Rui Barbosa (FCRB), ocorreu em 2016. A princípio, seriam lidas as correspondências, a fim de entender a relação de João Cabral com escritores homenageados em $(M T)$. Também, seriam comparados os manuscritos originais desse livro com a versão

\footnotetext{
${ }^{1}$ Doutora em Letras-Estudos Literários pela Universidade Federal de Minas Gerais (UFMG). Professora de Literatura, no Campus Montes Claros, do Instituto Federal do Norte de Minas Gerais (IFNMG). edneiarr@yahoo.com.br

${ }^{2}$ Estrofe do poema inédito "A Baudelaire”, encontrado na seção "Produção Intelectual”, do espólio documental de João Cabral de Melo Neto (JCMN), sob os cuidados do Arquivo-Museu de Literatura Brasileira (AMLB), da Fundação Casa de Rui Barbosa (FCRB). Neste trabalho, citações e referências a textos inéditos de João Cabral utilizarão essas abreviações.

${ }^{3}$ A partir da segunda menção, os títulos de livros de João Cabral serão abreviados: Museu de tudo (MT), A escola das facas (EF) e $\operatorname{Agrestes}(A)$.
} 
publicada em 1975 e consultado o documento “Museu da poesia”, indicado por Zila Mamede ${ }^{4}$ como um prefácio escrito por João Cabral para um livro homônimo do Willy Lewin.

À medida que a pesquisa avançava, as missivas adquiriram papel secundário diante das possibilidades que o material, listado em um inventário analítico de quase 600 páginas, tinha a oferecer. Aos poucos percebíamos que o espólio documental do poeta reservava um verdadeiro tesouro a ser escavado. Nessa primeira fase, foram identificados e transcritos três poemas, uma conferência e cerca de 30 textos curtos - artigos de jornal e programas de rádio ${ }^{5}$ - que não constam na obra completa ${ }^{6}$ nem em outros livros de João Cabral.

Inicialmente, foi consultada a seção "Produção Intelectual", mais precisamente pastas de "Obras literárias diversas: originais datilografados de prefácios, poesias, crônicas”. Essa etapa foi mais profícua para documentos em prosa. Em relação à poesia, somente "Versos de álbum", "Epitáfios" e "Poema-flash" não foram publicados em livros. Os demais manuscritos dessa pasta são poemas conhecidos ${ }^{7}$ ou versões com algumas mudanças, inclusive nos títulos, como: "Porque mataram o 'Cabeleira", "Vozes de Pernambuco" e "Pequeno museu andaluz". Como as versões modificadas de poemas não foram incluídas na Poesia completa $(2020)^{8}$, elas serão apresentadas de maneira mais detida em trabalhos futuros.

Dos três poemas encontrados em 2016, apenas a primeira parte de "Epitáfio" aparece na seção de Dispersos das edições de poesia completa de João Cabral (2008 e 2014), com o título "Ao Lêdo, em seu epitáfio", datado de junho de $1945^{9}$. Contudo, as partes sobre João Cabral e Antonio Rangel Bandeira permaneciam desconhecidas

\footnotetext{
${ }^{4}$ MAMEde, Zila. Civil Geometria: Bibliografia crítica, analítica e anotada de João Cabral de Melo Neto, 1942-1982. São Paulo: Nobel, 1987.

${ }^{5}$ Artigos de jornal: Preponderância da Poesia, O Romancista Otávio de Faria; Joaquim Cardozo [1952]; Os ensaios de crítica de poesia [Diário de Pernambuco]; Deolindo Tavares e sua poesia [Rev. Estudantes Recife]; Willy Lewin; Prática de Mallarmé [Renovação out. Nov. Dez. 42]; Sôbre a exposição de Portinari [O Jornal - 8.7.43]; As imaginações [A manhã];15 Poetas Catalães [Rev. Bras. Poesia].
}

Programas de rádio: O Romanceiro da Inconfidência, O Exílio das Elites, Um livro de Dantas [Mota]; Um poeta verdadeiramente moderno; Jacques Prévert, poeta moderno; Santa Cruz; Sôbre os críticos de poesia; O Amoroso e a Terra; Vinicius de Moraes; Geraldo Vidigal; O Romancista Otávio de Faria; Mauro Mota e a geração de 45; Sôbre o Romanceiro Popular; Poesia e Rádio; O Poeta Ciprinao Vitureira; Sôbre Poesia; Fim de uma etapa; Apresentação de Erskine Caldwell.

${ }^{6}$ Para esta pesquisa foram utilizadas as edições de 1986, 1994, 2008 e 2014.

${ }^{7} \mathrm{Na}$ mesma pasta em que se encontram três poemas inéditos, há estes de Museu de tudo (1975): "Para um cartão de Natal" (1952), até então sem título; "Acompanhando Max Bense em sua visita a Brasília” (1961); "A escultura de Mary Vieira” (Berna, 01/1967), poema-prefácio para o livro Polyvolume, de Mary Vieira; "Fábula de Rafael Alberti" (1947); "Fábula de Rafael Alberti” (1963) - presente em O tempo e modo do Brasil, Livraria Morais, Lisboa, 1967; Prefácio para um livro de gravuras de Vera Mindlin (Barcelona, dez. 1968); "Touro de lide”, publicado no Jornal do Fundão, no. 1107; "No centenário de Mondrian”; “Na morte de Marques Rebelo"; apresentação da "Exposição de Franz Weissman 7”, publicada no catálogo da exposição realizada na Galeria São Jorge, em Madrid, 1962.

${ }^{8}$ Lançada em novembro de 2020, pela Alfaguara, do grupo Companhia das Letras. O volume, organizado por Antonio Carlos Secchin, com a colaboração da autora deste trabalho, além dos 19 livros publicados pelo poeta, conta com Primeiros poemas (1990), duas publicações póstumas - Ilustrações para fotografia de Dandara (2011) e Notas para a possível A casa de farinha (2013) - e uma farta seção de poemas inéditos e dispersos.

9 “Ao Lêdo, em seu epitáfio" aparece também no texto "Chá com veneno - uma tarde de histórias e intrigas ao lado de Lêdo Ivo", publicado na Revista Piaú, edição 77, de fevereiro de 2013, acompanhado da seguinte informação: "João Cabral lhe ofereceu um epitáfio, riscado na folha de rosto de $O$ Engenheiro". Disponível em: <https://piaui.folha.uol.com.br/materia/cha-com-veneno/>. 
do público. O "Poema-flash", sobre a escritora Regina Célia Colônia ${ }^{10}$, foi publicado na contracapa do livro Os leões da Luziânia (1985), de autoria da homenageada. Trata-se, portanto, de um poema disperso.

Entre os achados de 2016, destaca-se um documento de 29 laudas datiloscritas, intitulado "A poesia brasileira". Essa conferência - "escrita no Recife, em 1954, mas nunca publicada", conforme anotações do próprio autor - redefiniu os rumos da pesquisa de doutorado. Como seriam analisados poemas para amigos escritores, a fim de indicar a intersecção entre poesia crítica e de circunstância, a opinião de João Cabral, nesse inédito, sobre poesia de circunstância precisaria ser levada em conta. Modificamos o plano de trabalho para investigar se houve algum evento em que João Cabral poderia ter apresentado essa conferência. No texto, há referências à capital de Pernambuco:

Mas já que estou falando do Recife, cidade maior de uma região que ainda conserva uma literatura popular viva, com seus poetas, seus editores, seus estilos, (literatura menos artificial na vida brasileira que a literatura requintada dos poetas eruditos), permito-me terminar com uma pergunta: por que não conciliar as formas dessa poesia narrativa com aquêles temas de local humanidade que fizeram a grandeza dos romancistas do nordeste? ${ }^{11}$

A partir de então, além de livros, entrevistas e cartas, voltamos nossa atenção para jornais e outros registros da época. Entre os documentos consultados, o Jornal Diário de Pernambuco, mesmo não trazendo pistas sobre a possível apresentação dessa conferência, reservou outra surpresa. A edição 00286, de 14 de dezembro de 1952, traz um pequeno ensaio, "Nota sobre a poesia taurina de Rafael Alberti". O referido texto não consta no inventário analítico do espólio documental de João Cabral, elaborado pelo AMLB da FCRB, nem é mencionado em sua obra completa ou em estudos bibliográficos a seu respeito, como Civil Geometria, de Zila Mamede. Tratase, portanto, de um texto disperso cuja publicação nesse jornal impediu que se perdesse definitivamente.

Em "A poesia brasileira”, João Cabral reflete sobre a produção poética no Brasil, em meados de 1950. Segundo ele, enquanto prestigiada por um grupo de seletos leitores, inclusive internacionalmente, nossa poesia não era capaz de alcançar o leitor brasileiro comum, conquistado pelo romance de 1930. Ao se afastar de temas ligados ao leitor anônimo, à medida que tomava o universo subjetivo do poeta e de seus pares como assunto principal, perdia-se o vínculo com o público e, consequentemente, a habilidade de comunicação que se espera de todo processo de escrita.

Ainda em 1954, durante o Congresso de Poesia de São Paulo, João Cabral apresenta a tese "Da função moderna da poesia" que, embora aborde alguns pontos explorados em "A poesia brasileira", bem como em "Poesia e composição" (1952), são textos diferentes entre si. A grande novidade dessa conferência inédita, se comparada à prosa publicada por João Cabral, consiste em relacionar o distanciamento entre a poesia brasileira e o leitor comum ao desinteresse do poeta por temáticas empíricas. Esse afastamento de assuntos voltados à

\footnotetext{
${ }^{10}$ A fim de não fugir da temática proposta para este trabalho, a análise do "Poema-flash" e o levantamento sobre a vida e a obra dessa escritora carioca serão abordados em trabalhos futuros.

${ }^{11}$ Texto inédito “A poesia brasileira”. In: FCRB, AMLB, JCMN, Seção “Produção Intelectual", pasta "Ensaio - Prosa de João Cabral de Melo Neto”, fl. 176.
} 
realidade imediata é considerado por João Cabral como poesia de circunstância ${ }^{12}$. A partir de tal ideia, propõe-se uma divisão entre poetas profissionais e bissextos, ou de circunstâncias, como se observa neste fragmento:

Quase que só há na poesia brasileira moderna poemas de circunstância. Há alguns exemplos em contrário, bons exemplos, embora raros. Mas apesar disso, a atitude característica do poeta brasileiro de hoje, mesmo daqueles oito ou dez grandes poetas em quem todos nós pensamos, sem falar, ainda há pouco, é uma atitude típica de poetas de circunstância. ${ }^{13}$

Não se explicita quais brasileiros poderiam ser considerados os oito ou dez "poetas profissionais", mas é possível supor que o próprio João Cabral e outras figuras conviviais, como Carlos Drummond de Andrade, Manuel Bandeira e Murilo Mendes, por exemplo, poderiam ser incluídos nesse grupo. Em determinada passagem do texto, ele sugere a frequência de publicação de livros e a dedicação constante ao trabalho de escrever como possíveis critérios para diferenciar os profissionais dos bissextos ${ }^{14}$. Ainda assim, tal segmentação se torna problemática, pois, mesmo mantendo certa frequência de publicação, as temáticas abordadas pelos possíveis membros do primeiro grupo continuam distantes do leitor e da realidade e, por isso, remetem ao circunstancial, segundo João Cabral:

Esse poeta que as condições políticas lançaram, temeroso, para dentro de si mesmo, e que procurou na filosofia dos poetas de outros países uma justificação para seu individualismo, já não pode libertar-se dele quando cessaram as condições que o tinham feito penetrar por tais caminhos. Esse poeta é o poeta bissexto de hoje, o poeta de domingo, categoria única entre os sócios desse grande clube de amadores de poesia a que está limitada nossa literatura de hoje. ${ }^{15}$

Há outros textos mais simples, com média de uma lauda, identificados como artigos de jornal ou programas de rádio. Em geral, versam sobre literatos, entre os quais Joaquim Cardozo, Otávio Faria, Luís Santa Cruz,

\footnotetext{
${ }^{12}$ A poesia de circunstância foi abordada de modo mais detido na tese de doutorado de minha autoria. Será brevemente retomada aqui a fim de apontar como as ideias de João Cabral se articulam com os principais estudiosos desse assunto. Pedrag Matvejevitch (1971) aponta três subgrupos da poesia de circunstância, referenciados nos níveis de dependência que o texto manterá com fatos externos, sugerindo uma progressiva liberdade do poeta em relação a eles: poesia cerimonial, poesia engajada e a que canta fatos da vida privada ou subjetiva. O segundo é exemplificado por Paul Éluard e o terceiro corresponde a "poesia de circunstância" eternizada por Johann Wolfgang Von Goethe: "Todos os meus poemas são poemas de circunstância, foram inspirados pela realidade e nela têm seu solo e seu fundamento” (ECKERMANN, 2017, p. 72). Os autores apontados por Matvejevitch, tanto aqueles que a defendem quanto os que a refutam, fundamentam sua argumentação com base na inserção do mundo empírico e na utilidade da poesia. Contraditoriamente, João Cabral contesta esse tipo de poesia por considerar que o poeta "bissexto", "amador" e "de domingo", criador dos versos de circunstância, não trata de temáticas extraídas da realidade imediata. Apesar da incompatibilidade em torno do conceito de poesia de circunstância, em relação à crítica ao afastamento do poeta de temas ligados à realidade do seu tempo, a opinião de João Cabral vai ao encontro das opiniões emitidas por Matvejevitch e Éluard.

${ }^{13}$ Melo Neto, Op. cit., fl. 150.

${ }^{14}$ Nesse ponto, mesmo que não haja menção explícita, a distinção entre poetas profissionais e bissextos, feita por João Cabral, lembra a Antologia de poetas brasileiros bissextos contemporâneos, publicada por Manuel Bandeira, em 1946: "bissexto é todo poeta que só entra em estado de graça de raro em raro".

${ }^{15}$ Melo Neto, Op. cit., fls. 156 e 157.
} 
Vinicius de Moraes e Cecília Meireles, por exemplo. Seguindo a ideia de que a poesia deveria estabelecer vínculos com a realidade, em "O exílio das elites" e "Romanceiro da Inconfidência", destaca-se a importância do poema histórico empreendido por Cecília Meireles, como se observa neste fragmento:

O aparecimento do "Romanceiro da Inconfidência" de Cecília Meireles pode ser considerado um dos acontecimentos mais importantes dos últimos anos. Pela primeira vez, o livro de um poeta brasileiro moderno vem mostrar que a poesia, mais do que uma substância determinada, é linguagem, isto é, uma maneira de falar de certos assuntos ou de transmitir certas substâncias. ${ }^{16}$

Entre idas e vindas, de 2016 a 2018, pesquisamos documentos de João Cabral nos arquivos da Casa Rui por algumas semanas. Quando parecia não haver motivos para encantamentos - apesar de o interesse por sua obra não ter cessado mesmo após dez anos de dedicação a ela - houve novas descobertas. Dezenas de poemas, ainda inéditos, alguns manuscritos de difícil entendimento e outros datiloscritos e bem organizados aguardavam por leitores. Dos poemas que se encontram em diferentes pastas da série Produção Intelectual, foram publicados: "A educação pela pedra", "Cemitério pernambucano" e "Tecendo a manhã" - da pasta "Poemas 1"; "Sevilha pintada de Brasília", "No círculo dos labradores" e "Gaiola de chuva" - da pasta de "Poemas 9"; e "Poucos sabem, mas existe um baobá no Recife" ${ }^{\text {"17 }}$. Naquela ocasião, identificamos e transcrevemos mais de cinquenta poemas que não aparecem em livros publicados pelo poeta, material que deixamos reservado para projetos futuros por não haver tempo hábil para acrescentá-lo às discussões da tese Um Museu de duas faces.

Alguns versam sobre escritores brasileiros, mesmo corpus da pesquisa de doutorado da autora deste trabalho. É o caso de "Mística na Bahia", subdividido em quatro partes ora sobre Vinicius de Moraes ora sobre Jorge Amado. Na última seção - 4- FIM DO JOGO - o sujeito poético dirige-se ao autor de Tieta do Agreste:

Jorge, certo não foi você:

nunca evitaste o ser-parecer.

Decerto foi uma mulher,

a mais égua, que Deus já fez ser,

digo égua, no melhor sentido, não porque se junta égua a vício,

\footnotetext{
${ }^{16}$ Texto inédito "Romanceiro da Inconfidência". In: FCRB, AMLB, JCMN, Seção "Produção Intelectual", pasta "Ensaio - Prosa de João Cabral de Melo Neto", fls. 49.

${ }^{17}$ Publicado na seção "Dispersos", da Poesia completa - João Cabral de Melo Neto (2014), p. 882. Na cópia datilografada consta um bilhete assinado por Marly de Oliveira: "Caro Arnaldo, espero que tenha feito boa viagem. Arranquei esse poema inédito do João quase à força, porque ele sempre acha que pode ser trabalhado ainda. Um abraço para toda a família (Está crescendo mesmo!) de Marly". Trata-se de Arnaldo Saraiva, escritor e professor lusitano, amigo de João Cabral, que o publica, juntamente com "Pedem-me um poema", no primeiro número de Terceira margem, Revista do Centro de Estudos Brasileiros da Faculdade de Letras da Universidade do Porto, em 1998.
} 


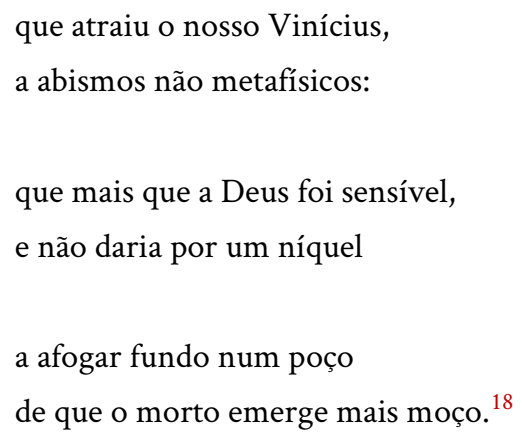

Trata-se da primeira referência ao escritor baiano na poesia de João Cabral. Para Antonio Carlos Secchin, o encadeamento sintático e a aversão à espontaneidade que levaram João Cabral a reverenciar Graciliano Ramos, ao passo que não mencionou Jorge Amado na sua poesia: "Você não tem um poema dele citando Jorge Amado. Vai encontrar um poema dele louvando Graciliano Ramos. Ele elogiava pouco a literatura brasileira" ${ }^{\prime 1}$.

O escritor brasileiro que aparece mais vezes na obra de João Cabral volta a ser homenageado nos inéditos "Joaquim Cardozo \& Quito [onde nunca esteve]" e "A nuvem sobre a batalha”. Nos textos em prosa, é tema do artigo de jornal, "Joaquim Cardozo" (1952). É importante destacar que, além de dedicatórias e menções ao longo da obra, Joaquim Cardozo é tema de seis poemas publicados por João Cabral: “A Joaquim Cardozo”; "Pergunta a Joaquim Cardozo"; “A luz em Joaquim Cardozo”; “Joaquim Cardozo na Europa”; "Na morte de Joaquim Cardozo"; e "Cenas da vida de Joaquim Cardozo".

Há poemas voltados a personalidades estrangeiras, algumas recorrentes nessa poética, como o toureiro Manuel Rodríguez - "As roupas de tourear de Manolete" - e o pintor Pablo Picasso - "Retrato de Picasso vestido de caçador" ${ }^{20}$. O poeta Charles Baudelaire, apesar da relevância na criação poética de João Cabral, é referenciado, de modo explícito, pela primeira vez no inédito "A Baudelaire". A semelhança entre o verso inicial - "Talvez, diante da folha em branco" - com o título "Diante da folha branca", de $(A)$, sugere que o inédito poderia ser a continuação desse poema que reflete sobre os processos criativos do poeta Stéphane Mallarmé e do pintor Vincent Van Gogh:

$$
\begin{aligned}
& \text { Diante da folha branca e virgem, } \\
& \text { na mesa, e de todo ofertada, } \\
& \text { com medo de que ela o sorvesse, } \\
& \text { ei-lo, como louco, a estruprá-la. }{ }^{21}
\end{aligned}
$$

Observa-se a retomada de assuntos caros à sua poética, como Pernambuco, a morte e o futebol. A terra natal aparece nos poemas "O cabocó", "Menino" e "De cão e de pulgas", além de alusões a familiares diluídas ao longo de outros poemas, como na contestação da genealogia dos Cabral de Melo, no irônico "Poema genealógico":

O que levo em mim do já não

\footnotetext{
${ }^{18}$ Melo Neto, João Cabral. Poesia completa. Rio de Janeiro: Editora Alfaguara, 2020. p. 826 e 827.

${ }^{19}$ SECCHIN apud VASCONCELOS, Selma. João Cabral de Melo Neto: retrato falado do poeta. Recife: Ed. do Autor, 2009 , p. 117.

${ }^{20}$ Poema citado por Rafaela Cardeal na dissertação de mestrado "Visita ao Museu de tudo, de João Cabral de Melo Neto" (2016), defendida na Universidade Federal do Rio de Janeiro (UFRJ), sob a orientação de Eucanaã Ferraz.

${ }^{21}$ Melo Neto, Op. cit., p. 639.
} 


\author{
Souza-Leão e Carneiro Leão? \\ Ou da inteligência sem credos \\ da avó Melo (não do que levo)? \\ Do mau humor Cabral de Melo, \\ que antes era Melo Azedo? \\ Ou dessa entreteia endogâmica, \\ de autobrancura em causa própria ${ }^{22}$
}

A respeito da morte, além de "O percevejo do mato", "A ressaca" e "O suicídio limpo", merece destaque "A inimiga íntima”, dedicado a Nelson Rodrigues. Trata-se de um dos poemas inéditos mais longos. As seis partes enumeradas buscam responder ao questionamento do primeiro verso:

\footnotetext{
Quantas mortes há numa morte?

Primeiro, há a morte ritual

do amigo que morre e que vamos

cobrir de ataúde e lençol; ${ }^{23}$
}

O futebol aparece em "Ciúme no campo do Arruda", como uma espécie de homenagem ao Estádio José do Rego Maciel, popularmente conhecido como Estádio do Arruda que é sede oficial do Santa Cruz Futebol Clube, time pelo qual João Cabral foi campeão juvenil em 1935.

Todavia, assuntos pouco explorados nos livros de João Cabral são notáveis nos seus inéditos. As guerras, por exemplo, que apareceu poucas vezes explicitamente ${ }^{24}$, surge em "A nuvem sobre a batalha":

Não há nuvem sobre a batalha.

Nas guerras de antes, sim havia.

Hoje na nuvem está a batalha

não a chuva que a ignoraria.

Hoje, ao pensar Joaquim Cardozo

o que me disse lembro, ainda,

dia que os jornais noticiaram

a nuvem caída em Hiroshima. ${ }^{25}$

\footnotetext{
${ }^{22}$ Melo NeTO, Op. cit., p. 835.

${ }^{23}$ Ibdem, p. 802.

24 Destacam-se "Episódio da Guerra Civil Espanhola”, de Crime na Calle Relator; "Guerra”, de Primeiros poemas; "O regimento", de Pedra do sono.

${ }^{25}$ Melo Neto, Op. cit., p. 804 e 805.
} 
A cidade do Rio de Janeiro, que recebeu breves menções, como no poema "Frei Caneca no Rio de Janeiro", de $(M T)$, agora aparece em "O dialeto", "Rio de Janeiro" e "A Deus, natural do Rio, São Paulo e Centro-Sul". Nos dois últimos prevalece o tom crítico em relação à cidade maravilhosa e à região Sudeste, acentuando ressalvas quanto à sua hegemonia política, cultural e socioeconômica, no contexto brasileiro. Em "O dialeto", ao expor seu dilema com variantes linguísticas, deixa escapar uma alfinetada no "esperanto carioca":

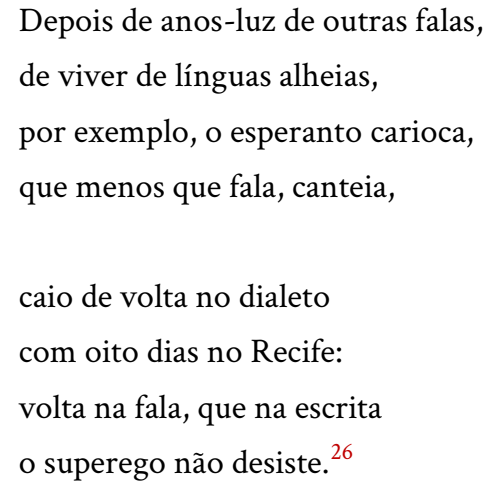

Aspectos envolvendo colegas do Itamaraty, suprimidos nos versos publicados pelo discreto João Cabral, emergem na série de quatro poemas intitulada "Memórias de um cônsul" (1, 2, 3, e 4). O mesmo pode ser observado no único voltado para a esfera familiar, um pequeno poema sem título, escrito para a filha, Inez Cabral:

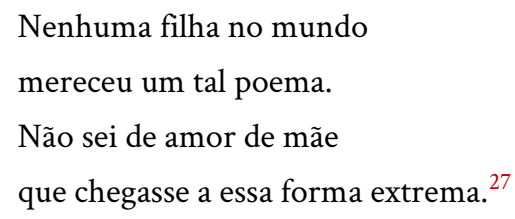

Os versos marcados pelo tom intimista do poema sobre a filha lembram aqueles com o qual o poeta homenageou a neta Dandara, na plaquete Ilustrações para fotografia de Dandara $(2011)^{28}$.

Alguns versos e títulos dos inéditos lembram outros já publicados, como trechos do poema "65 anos" que remetem à terceira parte de "O postigo", derradeiro poema de Agrestes (1985). Não se trata, portanto, de uma versão modificada desse poema apesar da semelhança temática. Outros três apresentam similaridades no título e no conteúdo, mas são diferentes no corpo do texto. É o caso dos inéditos "O suicídio limpo", "O Chimborazo como retórica" e "Ainda a retórica" que lembram "Sujam o suicídio", "O Chimborazo como tribuna" e "O ritmo do Chimborazo", todos do livro de 1985.

Em relação ao vulcão equatoriano, é importante destacar que o Equador, país onde João Cabral atuou como embaixador, de 1979 a 1981, é o tema mais recorrente entre os inéditos, totalizando sete poemas. Somente três a

\footnotetext{
${ }^{26}$ Ibdem, p. 830.

${ }^{27}$ Ibdem, p. 827.

${ }^{28}$ Quando atuava como embaixador do Brasil em Dacar, João Cabral escrevia poemas para ilustrar as fotografias da sua neta Dandara, que morava no Rio de Janeiro. Com doze textos manuscritos e as imagens da menina, enviadas por Inez Cabral, fez um pequeno álbum artesanal, intitulado Ilustrações para fotografias de Dandara, criado pela "Editora do Avô", em 1975. O livrinho, que revela o esmero e o afeto do avô-poeta, foi publicado pela editora Objetiva, em 2011.
} 
menos que aqueles publicados na seção "Viver nos Andes", de (A). É uma pena que os inéditos não tenham sido divulgados a tempo de compor a coletânea Vivir em los Andes: poemas equatorianos ${ }^{29}$, idealizada pelo atual embaixador do Brasil no Equador, João Almino. Trata-se de uma edição comemorativa do Centenário do nascimento de João Cabral, com tiragem de 1000 exemplares de distribuição gratuita.

Entre questionamentos que possam intrigar alguns e para os quais ainda buscamos respostas, destaca-se: por que ele não os publicou?. Algumas especulações podem nos ajudar a entender possíveis motivos que levaram esse material a permanecer desconhecido por quase 20 anos após a morte de João Cabral. Primeiramente, é importante lembrar que não estão reunidos em uma única pasta, somente com material inédito, como é o caso dos manuscritos de $A$ casa de farinha ${ }^{30}$, entregue pelo poeta à filha, Inez Cabral. Desta vez, trata-se de vários papéis avulsos localizados em diferentes seções e pastas, onde se encontravam misturados a textos conhecidos, como "A educação pela pedra" e "Tecendo a manhã", por exemplo.

Depois, embora apenas o poema "Entrevista" seja datado (8.10.87), com base na estruturação e nos temas próximos aos de $(A)$ e $(E F)$, pode-se inferir que a maior parte desses inéditos foi escrita entre 1980 e 1989. Essa possível data de elaboração vincula-se a um dado biográfico importante: a fase de adoecimento da primeira esposa do poeta, Stella Cabral de Melo, falecida, em 1986, vítima de um câncer. Figura importante na vida de João Cabral, por mais de quarenta anos, ela cuidara desde questões práticas da rotina do marido a aspectos envolvendo sua carreira literária, incumbindo-se de datilografar seus textos e organizar os manuscritos.

O último volume de Obra completa (1994) publicado por João Cabral foi organizado pela sua segunda esposa, a poeta Marly de Oliveira, com a assistência do autor. Nessa fase, o agravamento do quadro de degeneração macular comprometia bastante a visão do poeta, como se percebe neste depoimento, de 1997:

Passei a minha vida lendo. Não fiz outra coisa na minha vida, senão ler. E agora estou pagando por isso porque estou cego há uns quatro anos e não consigo ler, não consigo estar a par da literatura, não sei o que está se passando, inclusive, estou a esquecer de minha literatura. Às vezes, me lembro de um verso, mas não me lembro em que poema nem em que livro ele está. ${ }^{31}$

Apesar da dedicação de Marly de Oliveira, a edição de 1994 apresenta algumas fragilidades, que podem ajudar a compreender a ausência desses inéditos em livros publicados pelo poeta ainda em vida. Anotações de próprio

\footnotetext{
${ }^{29}$ Organizada por Renato Faria e Sonia Oliveira de Paredes, a edição bilíngue, traduzida para o espanhol por Iván Carvajal (poemas) e Alfonso Montúfar Estrella (textos), conta com texto de apresentação assinado por João Almino e ensaios de autoria de Iván Carvajal e Antonio Carlos Secchin. O livro com os dez poemas de Agrestes (1985) e um fac-símile de "A cana e o século dezoito”, de A escola das facas (1980), é ilustrado com reproduções de obras da artista equatoriana Araceli Gilbert e fotografias de Marcela García.

${ }^{30}$ Iniciado em 1966, esse livro inconcluso de João Cabral seria um auto, criticando as condições dos trabalhadores em fabriquetas de farinha nordestinas. No conjunto da obra do poeta, estaria na mesma linhagem de O cão sem plumas (1950), $O$ rio (1954), Morte e vida severina (1956) e Dois parlamentos (1961). Em 2013, a Alfaguara lançou uma versão fac-similar dos manuscritos, acompanhada de transcrições feitas pela organizadora, Inez Cabral, com o título Notas sobre a possível A casa de Farinha.

${ }^{31}$ Melo Neto, João Cabral. Entrevista. In: Linhares, Marcos. Cartas ao poeta dormindo: cartas a João Cabral de Melo Neto e entrevista inédita com o saudoso mestre da educação pela pedra. Brasília: Thesaurus, 2013. p. 57.
} 
punho $^{32}$, nas margens de algumas laudas datilografadas, indicam dúvidas sobre o que já havia sido publicado ou não. Os inéditos "Cais de Chelsea"33 e "De cão e de pulgas" trazem as seguintes anotações: "Revisto 2/8/91. Parece-me já publicado v. Museu de tudo" " "Revisto 2/8/1991. Acho que não foi publicado ainda. Rever Crime na Calle Relator". Por outro lado, na margem do poema "Gaiola de chuva", de Sevilha andando (1990) ${ }^{34}$, surge a expressão: "Não publicado!".

Independente dos motivos que levaram o poeta a não publicá-los em vida ou, ainda, o porquê de tais textos terem permanecido desconhecidos por tanto tempo, agora, esse material já pode ser apreciado pelos leitores. Cinquenta e três poemas inéditos e outros dispersos foram acrescentados à Poesia completa (2020). O volume já estava sendo organizado por Antônio Carlos Secchin - sumidade na obra de João Cabral - que, gentilmente, acolheu a proposta de inclusão do material escavado durante esta pesquisa na seção de Inéditos e Dispersos.

O fato de serem inéditos não representa poemas inacabados ou relegados pelo poeta porque se encontravam aquém do que ele sempre exigiu da sua poesia. Devido à diversidade temática e estética, se constituísse um livro independente, formariam uma coletânea mais heterogênea, similar a $(M T)$ e $(A)$ e a outros livros publicados no final da sua carreira literária. Portanto, são textos que, caso não venham acrescentar algo a, já consagrada, poesia cabralina, também não trazem elementos que possam comprometê-la.

Para João Cabral, a criação poética é resultado de trabalho árduo em vez de ser fruto do acaso e da inspiração. A pesquisa literária também pode ser considerada uma tarefa que demanda esforço e disciplina. Em certos aspectos, investigações em documentos de fontes primárias assemelham-se à prática de escavação. Às vezes, removemos muita terra e não encontramos nada, em outras nos deparamos com algumas preciosidades, como a conferência "A poesia brasileira" e mais de cinquenta poemas inéditos e dispersos. Assim, no centenário de nascimento de João Cabral, sua poesia - "com sua presença viva" - mostra que há muitos motivos para celebrações e investigações.

\footnotetext{
${ }^{32}$ Caligrafia similar àquela que se encontra no bilhete endereçado a Arnaldo Saraiva, enviando o poema "Poucos sabem, mas existe um baobá no Recife".

${ }^{33}$ Nota-se certa semelhança entre estes versos do poema inédito - "Das janelas sobre a maré/ têm outra maneira de olhar: sabem que o tempo é mais complexo/ do que o relógio faz pensar," - e a terceira estrofe do poema "Volta a Pernambuco": "As janelas do cais da Aurora,/ olhos compridos, vadios,/ incansáveis, como em Chelsea, veem rio substituir rios". Versão fac-similar de "Cais de Chelsea" pode ser conferida ao final deste trabalho.

${ }^{34}$ Apenas na Obra completa (1994) esse poema aparece em um livro intitulado Andando Sevilha. Na verdade, nunca foi um livro independente, trata-se de uma das seções de Sevilha andando (1989), dividido, originalmente, em duas partes: "Sevilha Andando" e "Andando Sevilha". Na edição de 1994, além de apresentar cada um dos segmentos como livro autônomo, acrescentou-se mais 15 poemas ao primeiro: Sevilha ao telefone, Sistema solar, Lições de Sevilha, Mulher cidade, Retrato, Poema, Ainda Sevilha ao telefone, Cidade viva, Sevilhana pintada em Brasília, O aire de Sevilha, Sal interior, Despertar com sevilhana, Sevilha revisitada em 1992, Oásis em Sevilha, Presença de Sevilha. Nas edições de Poesia completa (2008, 2014 e 2020), organizadas por Antonio Carlos Secchin, os 31 poemas de "Sevilha andando" e os 36 de "Andando Sevilha" integram um único livro - Sevilha andando - conforme o exemplar publicado pelo poeta em 1989.
} 
Manuscrítica § n. $42 \cdot 2020$

Artigos

revista de crítica genética

Documentos inéditos

1- Fac-símile de versão inicial do poema inédito "Cais de Chelsea". O original pertence ao espólio documental de João Cabral de Melo Neto, sob os cuidados do Arquivo-Museu de Literatura Brasileira, da Fundação Casa de Rui Barbosa.

an decelze,

n: o leater car de Lndis, no othan solteires do javelas ene olkw cmpil pe vi que tud (a o teupro!) F Pge deles.

as funels mbe os wares tê un othen diforlute is as alepes ne tir 6

$x$ tê ollur ds anb

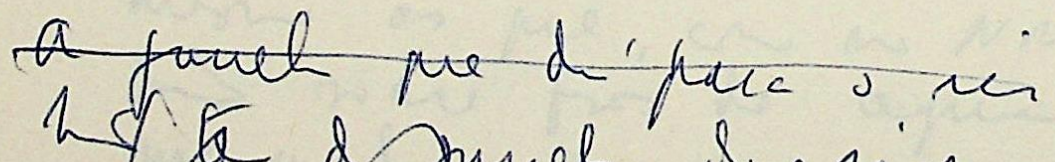

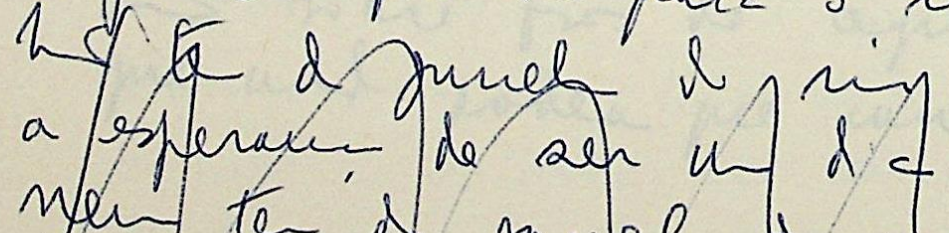
men te of gruel beb

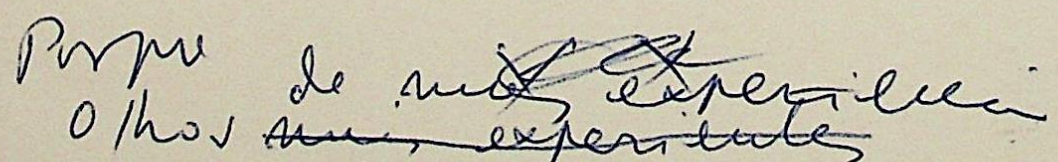
pace tods in tanques deap que nc se tz fiode ri or $<$ o nen,

que spas e imiens

O poeta no Museu: textos inéditos de João Cabral de Melo Neto

32 
2- Fac-símile da versão definitiva do inédito "Cais de Chelsea", também se encontra no Arquivo-Museu de Literatura Brasileira da Fundação Casa de Rui Barbosa.

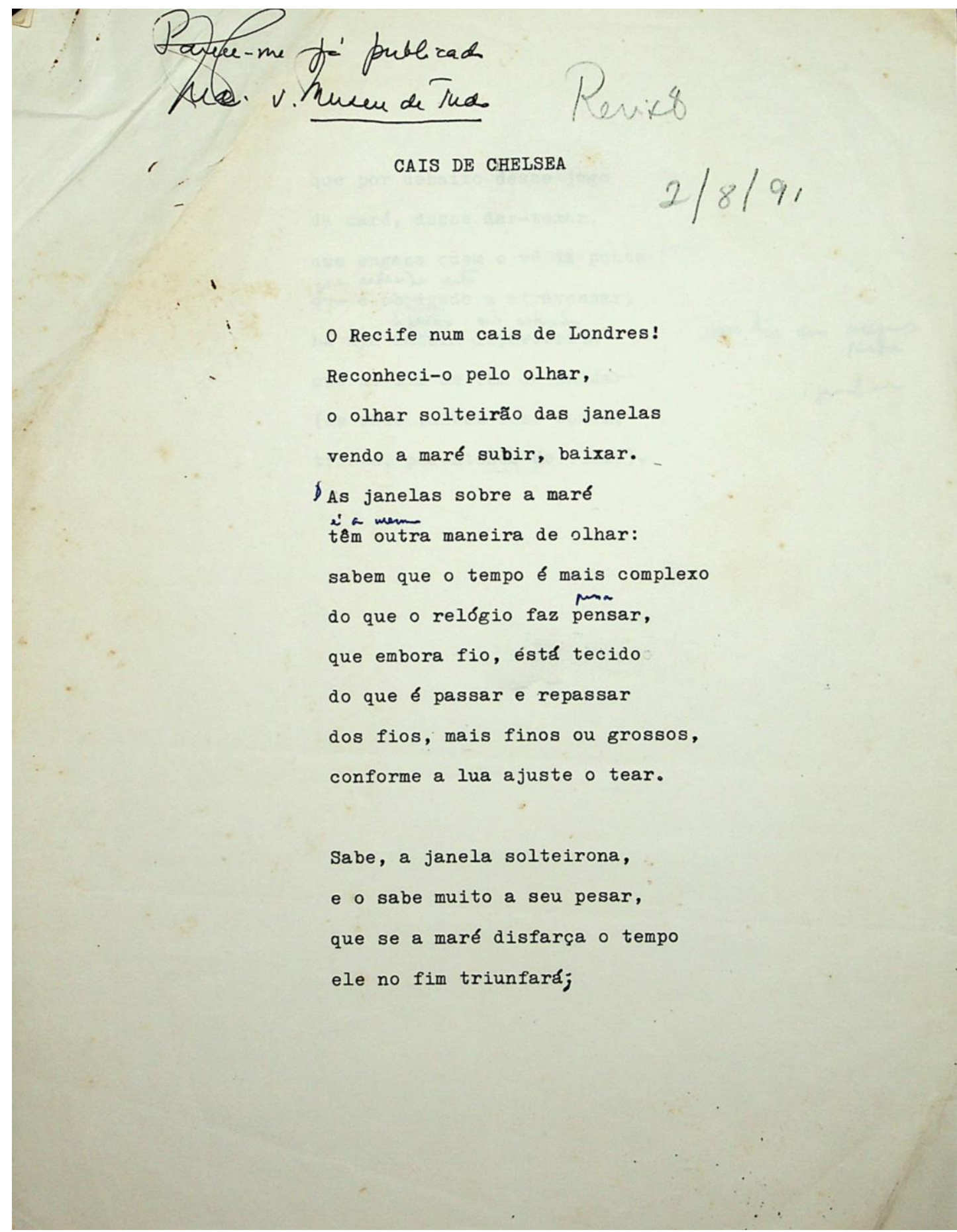




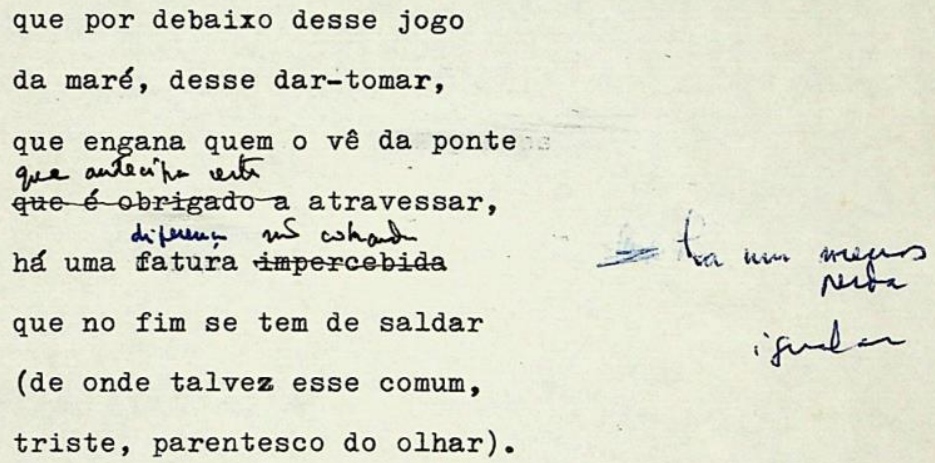

\section{Agradecimentos}

À Agência Riff e à Editora Alfaguara pela autorização para uso de fac-símile de manuscritos inéditos; ao Instituto Federal do Norte de Minas Gerais (IFNMG) pelo apoio para esta pesquisa; aos servidores da Fundação Casa de Rui Barbosa pela acolhida durante consultas ao arquivo; à Maria Alice Ribeiro Neves pela ajuda na transcrição dos originais, durante a pesquisa na Casa de Rui Barbosa. 


\section{Referências bibliográficas}

BANDEIRA, Manuel. Antologia de poetas brasileiros bissextos contemporâneos. Rio de Janeiro: Livraria editora Zelio Valverde, 1946.

Cardeal, Rafaela. Visita ao Museu de tudo, de João Cabral de Melo Neto. Dissertação (Mestrado em Letras Vernáculas), Universidade Federal do Rio de Janeiro (UFRJ), Rio de Janeiro, 2016.

ECKermann, Johann Peter. Conversações com Goethe nos últimos anos de sua vida 1823-1832. Tradução de Mario Luiz Frungillo. São Paulo: Editora Unesp Digital, 2017.

ÉLUARD, Paul. "Poésie de circonstance”. In: Oeuvres complètes. Paris: Gallimard, 1968, p. 931-945.

LEAL, Cláudio. “Chá com veneno - uma tarde de histórias e intrigas ao lado de Lêdo Ivo”. Revista Piauí, edição 77, fev. 2013. Disponível em: <https://piaui.folha.uol.com.br/materia/cha-com-veneno/>. Acesso 20/10/2017. Melo Neto, João Cabral. Ensaio: “Notas sobre a poesia taurina de Rafael Alberti”. In: Diário de Pernambuco, edição 00286, de 14/12/1952. Disponível em: <http://memoria.bn.br/DocReader/DocReader.aspx?bib=029033_13\&PagFis=0\&Pesq=notas\%20sobre\%20a\%20 poesia\%20taurina\%20de\%20rafael\%20alberti>. Acesso em: 12/01/2017.

Melo Neto, João Cabral. Conferência inédita: A poesia brasileira. In: FCRB, AMLB, Seção Produção Intelectual, pasta “Ensaio - Prosa de João Cabral de Melo Neto”. 1954, fls. 147-175.

Melo Neto, João Cabral. Programa de rádio: Romanceiro da Inconfidência. In: FCRB, AMLB, Seção Produção Intelectual, pasta “Ensaio - Prosa de João Cabral de Melo Neto”. s.d., fls. 49-50.

Melo Neto, João Cabral. Poema: “A respeito dos Leões da Luziânia”, in: ColÔNIA, Regina Célia. Os leões de Luiziânia: um conto de natal. Rio de Janeiro: José Olympio, 1985.

Melo Neto, João Cabral. Poesia completa (1940-1980). Lisboa: Imprensa Nacional - Casa da Moeda, 1986.

Melo Neto, João Cabral. Sevilha andando. Rio de Janeiro: Nova Fronteira, 1989.

Melo Neto, João Cabral. Obra completa. Org.: Marly de Oliveira. Rio de Janeiro: Nova Aguilar, 1994.

Melo Neto, João Cabral. Prosa. Org.: Marly de Oliveira. Rio de Janeiro: Nova Aguilar, 1997.

Melo Neto, João Cabral. Poesia completa e prosa. Org.: Antônio Carlos Secchin. 2. ed. Rio de Janeiro: Nova Aguilar, 2008.

MELO NeTO, João Cabral. Ilustrações para fotografias de Dandara. Rio de Janeiro: Objetiva, 2011.

Melo Neto, João Cabral. Notas sobre uma possivel A casa de farinha. Org. Inez Cabral. Rio de Janeiro: Objetiva, 2013.

Melo Neto, João Cabral. Entrevista, in: Linhares, Marcos. Cartas ao poeta dormindo: cartas a João Cabral de Melo Neto e entrevista inédita com o saudoso mestre da educação pela pedra. Brasília: Thesaurus, 2013.

Melo Neto, João Cabral. Poesia completa. Org.: Antonio Carlos Secchin. Rio de Janeiro: Academia Brasileira de Letras, 2014. Lisboa: Glaciar, 2014.

Melo Neto, João Cabral. Vivir en los Andes: Poemas Ecuatorianos (Edición conmemorativa del Centenario de su Nacimiento). Quito: Embajada del Brasil en Quito, 2020.

Melo Neto, João Cabral. Poesia completa. Org.: Antonio Carlos Secchin; com a colaboração de Edneia R. Ribeiro. Rio de Janeiro: Alfaguara, 2020. 
MAMEDE, Zila. Civil Geometria: Bibliografia crítica, analítica e anotada de João Cabral de Melo Neto, 1942-1982. São Paulo: Nobel, 1987.

MatVejevitch, Pedrag. Poésie de circonstance. Paris: Nizet, 1971.

Ribeiro, Edneia Rodrigues. Um museu de duas faces: poesia de circunstância em João Cabral de Melo Neto. 2019. Tese (Doutorado em Estudos Literários), Faculdade de Letras, Universidade Federal de Minas Gerais (UFMG), Belo Horizonte, 2019.

VASCONCElos, Selma. João Cabral de Melo Neto: retrato falado do poeta. Recife: Ed. do Autor, 2009. 